\title{
BMJ Open Retirement, job satisfaction and attitudes towards mandatory accreditation: a Danish survey study in general practice
}

Merethe Kirstine Andersen, ${ }^{1}$ Line Bjørnskov Pedersen, ${ }^{1,2}$ Frans Boch Waldorff ${ }^{1}$

To cite: Kirstine Andersen M, Pedersen LB, Waldorff FB. Retirement, job satisfaction and attitudes towards mandatory accreditation: a Danish survey study in general practice. BMJ Open 2018;8:e020419. doi:10.1136/ bmjopen-2017-020419

- Prepublication history for this paper is available online. To view these files, please visit the journal online (http://dx.doi. org/10.1136/bmjopen-2017020419).

Received 30 January 2018

Revised 10 May 2018

Accepted 25 June 2018

Check for updates

(C) Author(s) (or their employer(s)) 2018. Re-use permitted under CC BY-NC. No commercial re-use. See rights and permissions. Published by BMJ.

${ }^{1}$ Research Unit for General Practice, Institute of Public Health, University of Southern Denmark, Odense, Denmark ${ }^{2}$ COHERE - Centre of Health Economics Research, Institute of Public Health, University of Southern Denmark, Odense, Denmark

Correspondence to

Dr Merethe Kirstine Andersen; mkandersen@health.sdu.dk

\section{ABSTRACT}

Objectives This study aims to analyse the associations between general practitioner (GP) retirement, job satisfaction and attitudes towards a mandatory accreditation scheme. External interventions such as mandatory accreditation schemes may be perceived negatively by GPs, causing early retirement from practice. In Denmark, almost half of the GPs had negative attitudes prior to the implementation of a mandatory accreditation scheme, constituting a possible risk of early practice retirement.

Setting In January 2015 all 3,404 Danish GPs were invited to participate in a survey on attitudes towards a forthcoming mandatory accreditation programme. Participants $1,906 \mathrm{GPs}(56 \%)$ answered the questionnaire. In total, 391 (11\%) retired from practice in the following period from 1 January 2015 to 31 January 2017. Of these, 193 GPs (49\%) answered the questionnaire.

Primary and secondary outcome measures The primary outcome was GP retirement. Labour union data on practice retirement were linked with data from the questionnaire survey on job satisfaction and attitudes prior to implementation of mandatory accreditation. Logistic regression analyses were used to determine the associations between practice retirement and job satisfaction and attitudes towards accreditation.

Results Practice retirement was associated with job dissatisfaction (OR: 2.5, 95\% $\mathrm{Cl} 1.6$ to 3.7). Retirement was not associated with any of the other surveyed attitudinal variables. Retirement rate was relatively high in the accreditation start-up period.

Conclusion Practice retirement was associated with job dissatisfaction but not to a priori attitudes towards an upcoming mandatory accreditation programme. However, the retirement rate was relatively high in the start-up period of the accreditation programme. Future research should evaluate the effects of external interventions on preterm retirement from general practice.

Trial registration number NCT02762240.

\section{BACKGROUND}

Shortage of general practitioners

General practitioner (GP) shortage is a widespread problem leading to extra workload for the remaining GPs, which may eventually lead

\section{Strengths and limitations of this study}

This study is the first to analyse the associations between attitudes towards accreditation and retirement.

- The survey had a relatively high response rate also among those who subsequently retired.

Due to the cross-sectional nature of the study, it is not possible to conclude on causation.

- The generalisability of the findings may be limited to healthcare systems comparable with the Danish.

to preterm retirement. In UK a third of GPs are considering retirement, ${ }^{1}$ and the Association of American Medical Colleges foresees a shortage of as many as 65000 primary care physicians by $2025 .^{2}$

In Denmark there is also a present shortage of GPs, leaving patients in large geographical areas without a GP, the so-called ghost patients, and the Danish Health Authority expects the shortage to increase in the coming years. ${ }^{3}$ The education of a fully fledged GP takes a minimum of 6 years of postgraduate study, and solely increasing the uptake of medical students in universities cannot solve the problem right away. Therefore, it is highly requested that GPs continue working in their practices as long as possible. The mean age among Danish GPs in 2014 was 53.10 years (SD: 9.13$), 25 \%$ were older than 61 years, and $7.2 \%$ were older than 65 years.

\section{Practice retirement}

In a study from 2016 on the reasons of British GPs for leaving general practice, bureaucracy was under suspicion for causing early retirement. ${ }^{4}$ Another British study found that organisational changes had led to an increase in administrative tasks and overall workload, which was perceived by the GPs to have fundamentally changed the doctor-patient relationship. Lack of time with patients had 
compromised the ability to practise more patient-centred care, and with it GPs' sense of professional autonomy and values, resulting in diminished job satisfaction. ${ }^{5}$ Other explanations for cease of practice are increased working hours, burnout, job dissatisfaction, psychological distress and poor health. ${ }^{6}$

Danish GPs are allowed to sell their provider number and their office facilities whenever they wish, however encompassed by a number of rules determined by the Organisation of General Practitioners in Denmark (PLO). GPs are self-employed, so this transaction takes place without interference from public authorities. ${ }^{7}$

\section{Accreditation in general practice}

In 2016 a mandatory accreditation programme was rolled out as a stepwise process over 3 years in all general practices in Denmark. The mandatory nature of the Danish programme is rather exceptional as accreditation in the primary sector is generally non-government-funded and voluntary. ${ }^{8}$

The programme is embedded in the collective agreement between the PLO and their employer, Danish Regions, and is managed by the Danish Institute for Quality and Accreditation in Healthcare (IKAS) and in accordance with the national Danish Healthcare Quality Programme (DHQP). ${ }^{9}$ The DHQP comprises 16 standards for general practice, representing four themes: quality and patient safety, critical patient management, good continuity of care, and management and organisation of the clinic. GPs were notified about the accreditation year for their practice (which includes a surveyor visit) already in January 2015 to give them due time to work with the accreditation standards before the surveyor visit. GPs planning retirement within 5 years after the assigned accreditation date can apply for exemption from accreditation. A qualitative study on accreditation implementation strategies has pointed out as requisite that healthcare organisations should be capable of embracing accreditation if the implementation should succeed. ${ }^{10}$ The perceived comprehensiveness and the mandatory nature of the intervention may, however, challenge the implementation in Danish general practice.

\section{GPs' attitudes prior to the roll-out of a mandatory accreditation scheme}

A study on the attitudes of Danish GPs towards the forthcoming accreditation programme found that a total of 861 GPs $(45 \%)$ had negative attitudes towards the programme, whereas $23 \%$ had positive attitudes. Older GPs, male GPs and GPs working in single-handed practices were more likely to be negative towards accreditation. As for regional differences, $54 \%$ of the respondents in the Region of Northern Denmark had negative attitudes compared with $43 \%-46 \%$ in the other regions. ${ }^{11}$ Answers to open-ended questions (not published) revealed critical comments from GPs considering early retirement due to the perceived comprehensiveness of the accreditation programme.
In this study we aim to analyse the associations between job satisfaction, a priori attitudes towards the mandatory accreditation scheme and practice retirement.

\section{METHODS}

\section{Setting}

The Danish healthcare system is tax-financed and most GP and hospital services are free of charge. General practice is characterised by five key components: (1) a list system associating citizens with a GP (GPs can close for uptake when they have 1600 persons on the list but are allowed to enrol up to 2550 persons); (2) the GP acts as a gatekeeper and first-line provider in the sense that a referral from a GP is required for most office-based specialists and always for inpatient and outpatient hospital treatment; (3) an after-hours system staffed by GPs on a rotation basis; (4) a mixed capitation and fee-for-service system; and (5) GPs are self-employed, working within an agreement with the public funder. ${ }^{7}$

\section{Data collection}

We used data from a questionnaire study emailed to all 3403 Danish GPs affiliated with the PLO in January $2015 .^{12}$ The questionnaire study served as a baseline study regarding attitudes towards accreditation and job satisfaction, and was therefore carried out 1 year prior to accreditation start-up to avoid contamination in answers based on the timing of accreditation (the surveyor visit) in the individual practices.

Data on retirement from general practice in the period from January 2015 to January 2017, as well as data on gender, age and geographical localisation by region, were obtained from the PLO (table 1). We used retirement data from this period, as we expected retirement rates due to accreditation to be highest in the period immediately after the notification.

\section{Patient involvement}

Patients/service users/carers/lay people were not involved in the design of this study, and the development of outcome measures was not informed by patients' priorities, experience and preferences. Patients/carers/ lay people were also not involved in the recruitment to and conduct of the study. The results will be disseminated through scientific and trade journals, as well as other professional organisations. Patients/carers/lay people were not acknowledged in the contributorship statement/acknowledgements since they are not contributors.

\section{Survey design}

Healthcare researchers within the Research Units of General Practice in Odense, Aarhus and Copenhagen developed the questionnaire. ${ }^{12} \mathrm{~A}$ total of 13 items were included, representing the following themes: (1) attitudes towards various aspects of accreditation, (2) present organisation of specific tasks in the practice, (3) job satisfaction and (4) general practice organisation. A text field 
Table 1 Characteristics of retired general practitioners (GPs) and the remaining GPs

\begin{tabular}{|c|c|c|c|}
\hline \multirow[b]{3}{*}{ Characteristics } & Retired GPs & Remaining GPs & \multirow[b]{3}{*}{$P$ values } \\
\hline & $(n=391)$ & $(n=3012)$ & \\
\hline & n (\%) & n (\%) & \\
\hline Age & & & $<0.001$ \\
\hline Below 45 & $25(6.4)$ & $880(29.2)$ & \\
\hline $46-55$ & 39 (10.0) & $949(31.5)$ & \\
\hline $56-65$ & $221(56.5)$ & $1045(34.7)$ & \\
\hline 66 and above & $106(27.1)$ & $138(4.6)$ & \\
\hline Mean (SD) (range) & $61.4(7.1)(38-77)$ & $52.0(8.8)(33-84)$ & $<0.001$ \\
\hline Gender & & & $<0.001$ \\
\hline Female & 150 (38.4) & $1494(49.6)$ & \\
\hline Male & $241(61.6)$ & $1518(50.4)$ & \\
\hline Practice type & & & $<0.001$ \\
\hline Shared & $211(54.0)$ & $2111(70.1)$ & \\
\hline Solo practice & $180(46.0)$ & 901 (29.9) & \\
\hline Region & & & 0.058 \\
\hline $\begin{array}{l}\text { Capital Region of } \\
\text { Denmark }\end{array}$ & $137(35.0)$ & 887 (29.5) & \\
\hline $\begin{array}{l}\text { Central Denmark } \\
\text { Region }\end{array}$ & $88(22.5)$ & $711(23.6)$ & \\
\hline $\begin{array}{l}\text { Region of North } \\
\text { Denmark }\end{array}$ & $43(11.0)$ & $272(9.0)$ & \\
\hline Region Zealand & 45 (11.5) & $430(14.3)$ & \\
\hline $\begin{array}{l}\text { Region of Southern } \\
\text { Denmark }\end{array}$ & $78(20.0)$ & 712 (23.6) & \\
\hline $\begin{array}{l}\text { Response to } \\
\text { questionnaire }\end{array}$ & & & 0.005 \\
\hline Responders & $193(49.4)$ & $1713(56.9)$ & \\
\hline Non-responders & $198(50.6)$ & $1299(43.1)$ & \\
\hline
\end{tabular}

(with unlimited space) for comments was inserted after all items. In the present study we used 5 out of 13 items in our analyses. The wording and response categories are displayed below:

1. How satisfied are you all in all with your job as a GP? Response categories: very satisfied, satisfied, dissatisfied, very dissatisfied, do not know.

2. How will you describe your attitude towards accreditation in general practice? Response categories: very positive, positive, neutral, negative, very negative, do not know.

3. Accreditation is a tool for quality improvement in general practice. Response categories: much agree, agree, neutral, disagree, much disagree, do not know.

4. Accreditation is a tool for external control of general practice. Response categories: much agree, agree, neutral, disagree, much disagree, do not know.

5. How do you think the process forward towards accreditation will affect your job satisfaction as a GP? Response categories: very positively, positively, neutrally, negatively, very negatively, do not know.

A pilot test focusing on content validity, relevance, acceptability and feasibility was conducted among nine GPs from four of the five regions in Denmark. Only minor changes were made hereafter. Additionally, the question surveying job satisfaction was further tested in a recent survey on GPs' job satisfaction in relation to task delegation. ${ }^{13}$ Data on responders versus non-responders to the questionnaire are shown elsewhere. ${ }^{11}$

\section{Statistical analysis}

Using univariate analyses, we compared gender, age, region and practice type between retired GPs and non-retired GPs by means of $\chi^{2}$ tests. Response rates between the two groups were also compared by means of $\chi^{2}$ test.

We estimated a Kaplan-Meier survival curve to explore the retirement pattern in the period from the distribution of the questionnaire in January 2015 to January 2017 and calculated survival rates at two different points in time (January 2016 and January 2017).

In five binary logistic regression analyses, we used practice retirement as our dependent variable, and one measure of general job satisfaction and four different measures of attitudes and expectations towards accreditation as our explanatory variables. These are described in the Survey design section. The attitudinal variables were dichotomised. The five analyses were subsequently adjusted for age, gender, practice type and region. Collinearity was tested using the Collin command on Stata V.15. We used robust SEs clustered on practice level to allow for intragroup correlation in the general practices.

Data were analysed on Stata V.15 statistical software.

\section{RESULTS}

Out of 3,403 survey invitations sent, a total of 1,906 respondents $(56 \%)$ completed the questionnaire. In the period from January 2015 to January 2017, a total of 391 GPs retired from practice, of whom 193 (49\%) had completed the questionnaire.

The retired GPs differed significantly from the remaining GPs with regard to age, gender, practice type and response rate (table 1). Sixteen per cent (16.4\%) of the retired GPs were below the age of 55 .

Figure 1 shows that there has been a linear retirement rate in Danish general practice in most of the period from 1 January 2015 to 1 January 2017. However, an increased retirement rate was observed around January 2016, when the accreditation programme was initiated. Survival analyses show that the increased retirement rate in January 2016 was 0.08 (95\% CI 0.06 to 0.1 ), whereas the retirement rate in January 2017 was 0.04 (95\% CI 0.03 to 0.05 ).

Table 2 shows that almost half $(45.2 \%)$ of the GPs had a negative attitude towards accreditation, and that a majority $(81.7 \%)$ perceived accreditation as a tool for external control, while only $41.2 \%$ perceived accreditation as a tool for quality improvement. Practice retirement was associated with job dissatisfaction (adjusted OR: 2.5, 95\% CI 1.6 to 3.7). However, $82 \%$ reported being satisfied with their job. Retirement was not statistically significantly associated with any of the surveyed attitude 


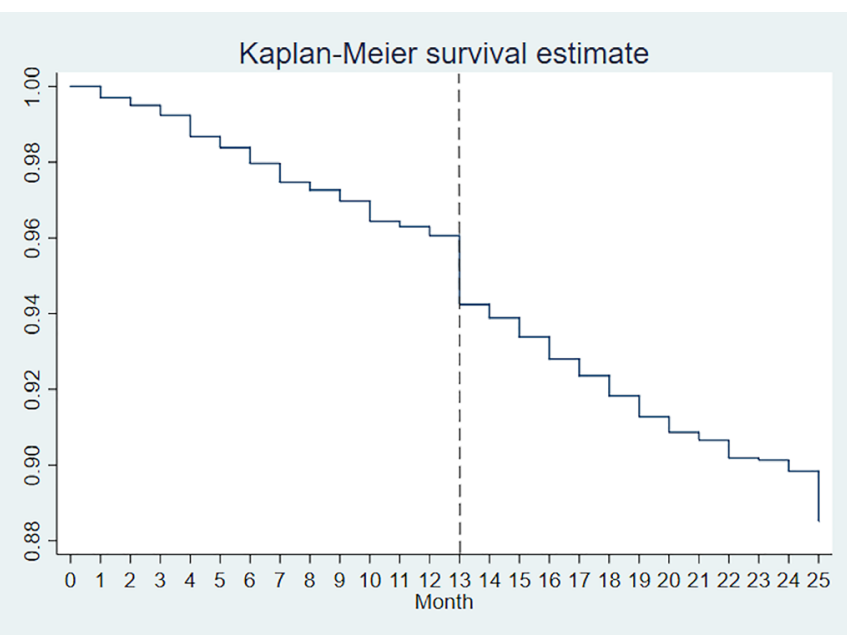

Figure 1 Overview of general practitioner employment pattern from 1 January 2015 to 31 January 2017.

variables related to accreditation in the adjusted analyses (table 3).

\section{DISCUSSION}

\section{Main results}

We surveyed the attitudes of GPs towards an upcoming mandatory accreditation programme as well as their overall job satisfaction, and linking these survey data with retirement data we found an association between retirement and job dissatisfaction. A more surprising finding was that retirement was not statistically significantly associated with negative attitudes towards the mandatory accreditation programme. However, survival analysis indicated a relatively high retirement rate around the time of accreditation start in January 2016. Although the Danish general practice has gone through some turbulent years, we dare not to draw conclusions on to what extent this explains the transient increase in the retirement rate in January 2016. More male GPs than female GPs retired in this period. This may be explained by the fact that the majority of older GPs are men.

\section{Other studies}

A recent longitudinal study on American physicians and advance practice providers found that those who indicated increased job satisfaction within the follow-up period were over eight times as likely to indicate reduced intention to leave their practices, compared with clinicians whose satisfaction did not increase. ${ }^{14}$ An Australian study found that declining job satisfaction, falling workforce numbers, excessive workload and increasing bureaucracy were recurrent concerns of older GPs considering premature retirement. Moreover, 65\% mentioned increasing bureaucracy, poor job satisfaction and disillusionment with the medical system or Medicare as obstacles to working in general practice. ${ }^{15}$ This study, however, surveyed intentions of early retirement, while our study surveyed actual practice retirement. Accreditation can be thought of as increased bureaucracy, and we did not
Table 2 Descriptive statistics

\begin{tabular}{|c|c|}
\hline \multirow[b]{2}{*}{ Characteristics } & \multirow{2}{*}{$\begin{array}{l}\text { Responding genera } \\
\text { practitioners }\end{array}$} \\
\hline & \\
\hline \multicolumn{2}{|l|}{ Job satisfaction } \\
\hline Satisfied & $1558(81.7)$ \\
\hline Dissatisfied & $231(12.1)$ \\
\hline Do not know & $47(2.5)$ \\
\hline Missing & $70(3.7)$ \\
\hline \multicolumn{2}{|l|}{ Attitude towards accreditation } \\
\hline Positive & $429(22.5)$ \\
\hline Negative & $861(45.2)$ \\
\hline Neutral/do not know & $616(32.3)$ \\
\hline \multicolumn{2}{|l|}{$\begin{array}{l}\text { Accreditation is a tool for external } \\
\text { control }\end{array}$} \\
\hline Agree & $1558(81.7)$ \\
\hline Disagree & $76(4.0)$ \\
\hline Neutral/do not know & $234(12.3)$ \\
\hline Missing & $38(2.0)$ \\
\hline \multicolumn{2}{|l|}{$\begin{array}{l}\text { Accreditation is a tool for quality } \\
\text { improvement }\end{array}$} \\
\hline Agree & $785(41.2)$ \\
\hline Disagree & $565(29.6)$ \\
\hline Neutral/do not know & $518(27.2)$ \\
\hline Missing & $38(2.0)$ \\
\hline \multicolumn{2}{|c|}{$\begin{array}{l}\text { How do you think the accreditation } \\
\text { process will affect your job } \\
\text { satisfaction? }\end{array}$} \\
\hline Positively & $116(6.1)$ \\
\hline Negatively & $1095(57.5)$ \\
\hline Neutrally/do not know & $632(33.2)$ \\
\hline Missing & $63(3.3)$ \\
\hline \multicolumn{2}{|l|}{ Age } \\
\hline Below 45 & $478(25.1)$ \\
\hline $46-55$ & $559(29.3)$ \\
\hline $56-65$ & 749 (39.3) \\
\hline 66 and above & $120(6.3)$ \\
\hline Mean (SD) (range) & $53.3(8.9)(33-84)$ \\
\hline \multicolumn{2}{|l|}{ Gender } \\
\hline Female & $913(47.9)$ \\
\hline Male & $993(52.1)$ \\
\hline \multicolumn{2}{|l|}{ Practice type } \\
\hline Shared & $1309(68.7)$ \\
\hline Solo practice & $597(31.3)$ \\
\hline \multicolumn{2}{|l|}{ Region } \\
\hline Capital Region of Denmark & $572(30.0)$ \\
\hline Central Denmark Region & $473(24.8)$ \\
\hline Region of North Denmark & $171(9.0)$ \\
\hline Region Zealand & 265 (13.9) \\
\hline Region of Southern Denmark & $425(22.3)$ \\
\hline
\end{tabular}


Table 3 Associations between general practitioner retirement and attitudes towards accreditation

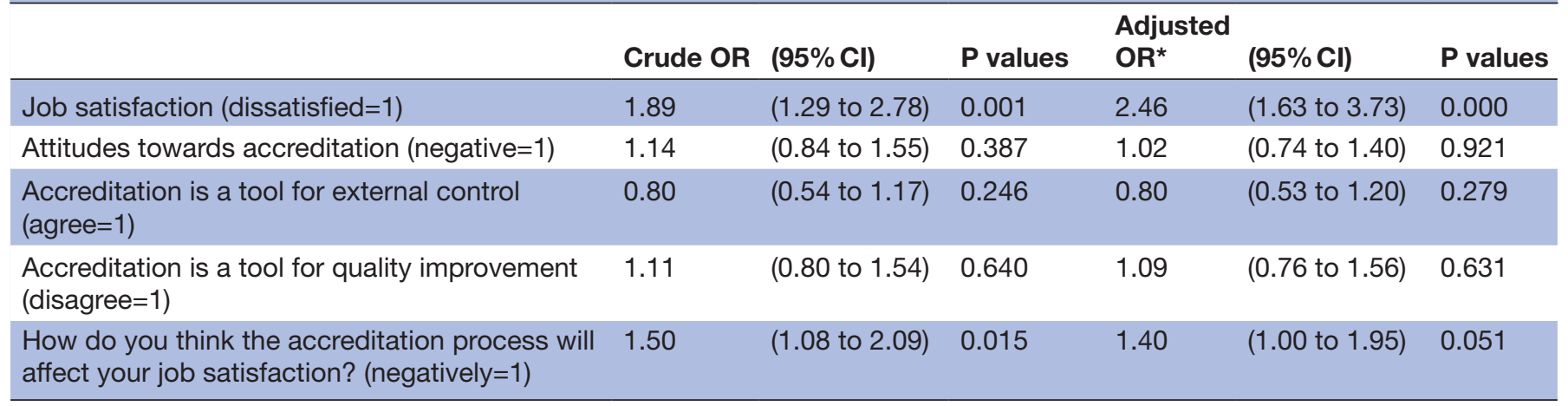

${ }^{*}$ Adjusted for age, gender, practice type and region.

find associations between the attitudes towards accreditation and practice retirement. A US study evaluated the effects of healthcare changes on physician retirement and found that while managed care was an important factor for physicians' retirement decisions, it did not necessarily lead to earlier retirement. ${ }^{16}$ Another US study on more than 8000 practising paediatricians' retirement plans revealed that $27 \%$ would retire if it were affordable. Moreover, increasing regulations were the most frequent cause for retiring given by retired paediatricians. ${ }^{17}$

Between 2009 and 2014, 45.5\% of the 12690 English GPs leaving general practice were below 50 years, $30.6 \%$ were aged $50-59$ years, and less than a quarter were above 60 years. $^{18}$

Reasons for leaving general practice among English GPs below the age of 50 years were, among others, increase in administrative tasks and overall workload. Lack of time with patients and decreasing sense of professional autonomy and values had resulted in diminished job satisfaction. ${ }^{5}$

\section{Strengths}

Our survey revealed a relatively high response rate, even among GPs who retired from practice in the following period. To our best knowledge, this study is the first to analyse the associations between attitudes towards external interventions and retirement.

\section{Limitations}

Due to the cross-sectional nature of our study, we are not able to conclude on causation.

More remaining GPs than retiring GPs completed the survey, which may have caused selection bias. If retiring non-responding GPs are more critical towards accreditation, our results may underestimate the association between negative attitudes towards accreditation and retirement.

We used only one question on overall job (dis)satisfaction. It has been suggested, however, that rating of overall job satisfaction may be a more inclusive measure of overall job satisfaction than a summation of many facet responses. $^{19}$
The generalisability of our findings may be limited to healthcare systems comparable with the Danish. Moreover, the Danish GPs have favourable job possibilities if they want to work in other Nordic countries or in hospitals. Hence, they are not forced to accept external interventions when it comes to earning one's living. This may not be the case in countries with unemployment among GPs or with infrastructure or legislation that does not allow for mobility of the workforce.

Our data show retirement from GPs' own practice, but we cannot tell if the GPs have retired completely or have taken locum employment within another practice. As we do not have data on GPs who have applied for exemption from accreditation, we are not able to assess how many GPs are still working in general practice under exemption.

We used retirement data from January 2015 to January 2017, as we expected retirement rates due to accreditation to be highest in the period immediately after the notification and did not find any statistically significant association between attitudes towards accreditation and retirement. However, we found an association between retirement and having negative expectations towards the effect of accreditation on job satisfaction. Although this association was not statistically significant $(p=0.051)$, it is not a strong proof of a lack of an association. Since satisfaction in our study is associated with intent to retire, the programme could lead to an increase in retirement until December 2018. Hence, there is a risk that we do not capture the full effect on retirement in our study, and we will need to watch over time to see if the programme leads to a drop in satisfaction, which would then eventually lead to increased numbers of physicians retiring.

\section{Implications}

Our results show a much lower retirement rate among the youngest GPs than in the UK. Nevertheless, the challenges facing Danish GPs may mirror the ones experienced by English GPs, and the UK conditions should be a grave reminder of the constraints presumably also meeting Danish GPs.

Our results showing that retirement was associated with job dissatisfaction are important knowledge that should 
be taken into account when working out agreements and legislations for primary care. If job satisfaction in itself counteracts retirement, even when an external intervention is carried out, it is highly recommended that job satisfaction is maintained.

We only surveyed the associations of attitudes towards accreditation and retirement. It should be kept in mind that GPs, as other people, might also experience others factors that attract retirement, for example, wishing to spend more time with family, enjoying life and so on. ${ }^{20}$

\section{Perspectives}

Although our study design does not allow for causal conclusions, it may raise questions on the causes of practice retirement such as external interventions that may give rise to negative expectations or general job dissatisfaction. Future research should focus on how these factors can be influenced to avoid preterm retirement and further GP shortage.

\section{CONCLUSION}

Practice retirement was associated with job dissatisfaction but not with a priori attitudes towards an upcoming mandatory accreditation programme. However, the retirement rate was relatively high in the start-up period of the accreditation programme, and future research should evaluate the effects of external interventions on preterm retirement from general practice.

Acknowledgements We wish to thank the participating GPS.

Contributors MKA participated in the design of the study, developed the outcomes and drafted the paper. LBP participated in the design of the study, developed the outcomes, performed the analyses and critically revised the paper. FBW participated in the design of the study, developed the outcomes and critically revised the paper. All authors read and approved the final manuscript.

Funding This research received an unrestricted grant from the Danish Institute for Quality and Accreditation in Healthcare (IKAS) and the Danish Research Foundation for General Practice. Apart from this, we received no specific grant from any funding agency in the public, commercial or not-for-profit sectors.

Competing interests None declared.

Patient consent Not required.

Ethics approval The Research Ethics Committee for the Region of Southern Denmark has approved the study (file number S-20152000-178) and the Danish Data Protection Agency (J.nr. 2016-41-4579) according to the personal data law $\S 50$, part 1 , number 1 .

Provenance and peer review Not commissioned; externally peer reviewed.
Data sharing statement The data are stored at the Research Unit of General Practice, University of Southern Denmark, but are not available due to Danish legislations. FBW is responsible for the data, which are all anonymised.

Open access This is an open access article distributed in accordance with the Creative Commons Attribution Non Commercial (CC BY-NC 4.0) license, which permits others to distribute, remix, adapt, build upon this work non-commercially, and license their derivative works on different terms, provided the original work is properly cited, appropriate credit is given, any changes made indicated, and the use is non-commercial. See: http://creativecommons.org/licenses/by-nc/4.0/.

\section{REFERENCES}

1. Rimmer A. A third of GPs are considering retirement, BMA survey finds. BMJ 2015;350:h2037.

2. Mullangi S, Saint S. Applying organizational behavior theory to primary care. Am J Manag Care 2017;23:194-6.

3. Authority S-DHaM.. Physician prognosis - the supply of physicians and specialists 2012-2035: The National Board of Health, 2013.

4. Rimmer A. Bureaucracy is forcing GPs to quit under "euphemism of early retirement". BMJ 2015;350:h2466.

5. Doran N, Fox F, Rodham K, et al. Lost to the NHS: a mixed methods study of why GPs leave practice early in England. Br J Gen Pract 2016;66:e128-e135.

6. Pit SW, Hansen V. Factors influencing early retirement intentions in Australian rural general practitioners. Occup Med 2014;64:297-304.

7. Pedersen KM, Andersen JS, Søndergaard J. General practice and primary health care in Denmark. J Am Board Fam Med 2012;25(Suppl 1):S34-8.

8. O'Beirne M, Zwicker K, Sterling PD, et al. The status of accreditation in primary care. Qual Prim Care 2013;21:23-31.

9. IKAS. The Danish Healthcare Quality Programme. 2015.

10. Hinchcliff R, Greenfield D, Westbrook JI, et al. Stakeholder perspectives on implementing accreditation programs: a qualitative study of enabling factors. BMC Health Serv Res 2013;13:437.

11. Waldorff FB, Nicolaisdóttir DR, Kousgaard MB, et al. Almost half of the Danish general practitioners have negative a priori attitudes towards a mandatory accreditation programme. Dan Med J 2016;63.

12. group TA. Attitudes towards a mandatory accreditation program questionnaire. 2015. http://www.akiap.dk/wp-content/uploads/2016/ 06/APPENDIX_AKIAP.pdf

13. Riisgaard H, Søndergaard J, Munch M, et al. Associations between degrees of task delegation and job satisfaction of general practitioners and their staff: a cross-sectional study. BMC Health Serv Res 2017;17:44.

14. Linzer M, Sinsky CA, Poplau S, et al. Joy in medical practice: clinician satisfaction in the healthy work place trial. Health Aff 2017;36:1808-14.

15. Brett TD, Arnold-Reed DE, Hince DA, et al. Retirement intentions of general practitioners aged 45-65 years. Med J Aust 2009;191:75-7.

16. Bahrami B, Elder J, Jacobson S. Change in the U.S. health care system: effects on physician retirement and implications for health care managers. J Health Hum Serv Adm 2002;25:342-70.

17. Rimsza ME, Ruch-Ross $\mathrm{H}$, Simon HK, et al. Factors influencing pediatrician retirement: a survey of american academy of pediatrics chapter members. J Pediatr 2017;188:275-9.

18. NHS. General and personal medical services, England - 2004-2014. NHS - UK: NHS Staff 2004 - 2014 publication. NHS digital, 2015.

19. Scarpello V, Campbell JP. Job satisfaction: are all the parts there? Pers Psychol 1983;36:577-600.

20. Reeuwijk KG, de Wind A, Westerman MJ, et al. 'All those things together made me retire': qualitative study on early retirement among Dutch employees. BMC Public Health 2013;13:516. 